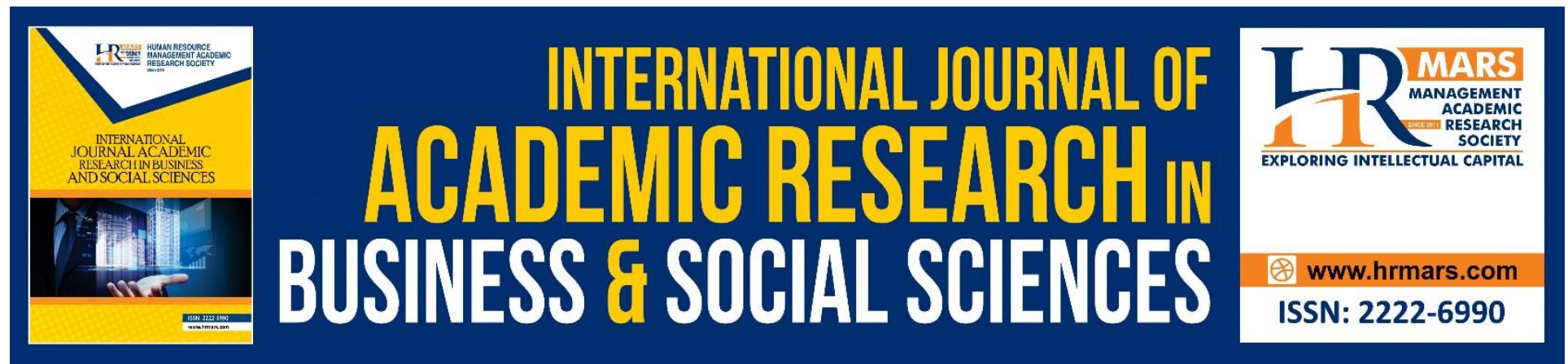

\title{
The Relationship Between Emotional Dysregulation and Aggressive Behavior among Adolescents
}

\section{Intan Raihan Darmadi \& Abdul Rahman Ahmad Badayai}

To Link this Article: http://dx.doi.org/10.6007/IJARBSS/v11-i6/10238

DOI:10.6007/IJARBSS/v11-i6/10238

Received: 12 April 2021, Revised: 15 May 2021, Accepted: 29 May 2021

Published Online: 19 June 2021

In-Text Citation: (Darmadi \& Badayai, 2021)

To Cite this Article: Darmadi, I. R., \& Badayai, A. R. A. (2021). The Relationship Between Emotional

Dysregulation and Aggressive Behavior among Adolescents. International Journal of Academic Research in Business and Social Sciences, 11(6), 1054-1064.

Copyright: (C) 2021 The Author(s)

Published by Human Resource Management Academic Research Society (www.hrmars.com)

This article is published under the Creative Commons Attribution (CC BY 4.0) license. Anyone may reproduce, distribute, translate and create derivative works of this article (for both commercial and non-commercial purposes), subject to full attribution to the original publication and authors. The full terms of this license may be seen at: http://creativecommons.org/licences/by/4.0/legalcode

Vol. 11, No. 6, 2021, Pg. 1054- 1064

http://hrmars.com/index.php/pages/detail/IJARBSS

JOURNAL HOMEPAGE

Full Terms \& Conditions of access and use can be found at http://hrmars.com/index.php/pages/detail/publication-ethics 


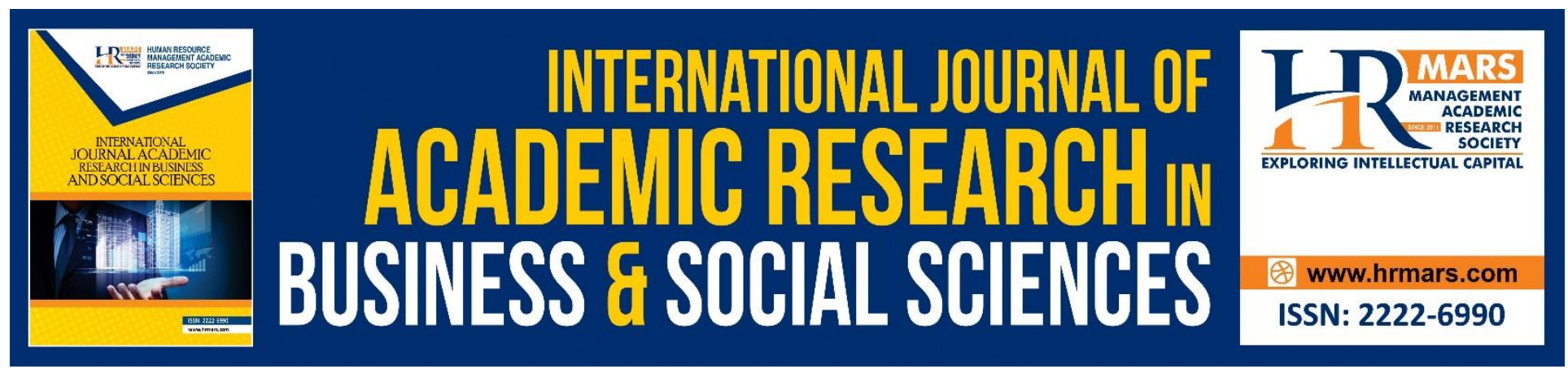

\title{
The Relationship Between Emotional Dysregulation and Aggressive Behavior among Adolescents
}

\author{
Intan Raihan Darmadi \& Abdul Rahman Ahmad Badayai \\ Centre of Research for Psychology and Human Well-Being, Faculty of Social Sciences and \\ Humanities, The National University of Malaysia \\ Email: arab5487@ukm.edu.my
}

\begin{abstract}
Adolescence is a crucial developmental stage during which any adolescent undergoes biological, psychological, and, most importantly, emotional changes. During this time, teenage life is more based on external pressures that trigger an unhealthy emotional and cognitive state, either directly or indirectly. Therefore, the aim of this study was to look into the connection between emotional dysregulation and aggressive behavior in adolescents. This study employed a survey design by distributing questionnaires to 159 adolescents. The questionnaire comprised three parts namely demographic profile, emotional dysregulation, and aggressive behavior. As a result, emotional dysregulation was found to be strongly linked to aggressive behavior. These results suggest that emotional dysregulation plays an important role in adolescent aggression by teaching them how to efficiently regulate their emotions and therefore avoid aggressive behavior. These findings further imply the importance of the role of emotional dysregulation among adolescents so that they know how to overcome aggressive behavior by regulating their emotions effectively.

Keywords: Emotional Dysregulation, Aggressive Behavior, Adolescent, Emotional Changes, Regulate

\section{Introduction}

Adolescence has been described as a period of "storm and stress," during which adolescents face challenging life experiences and is often associated with certain life conflicts, such as conflict with parents (Gecas and Seff, 1990; Steinberg, 1987), emotional uncertainty (Larson and Richards, 1994), negative affect (Brooks-Gunn \& Warren, 1989; Buchanan, Eccles, and Becker, 1992; Petersen et al., 1993), and risky behavior (Arnett, 1992; Moffitt, 1993). Adolescents are often said to be in the experimentation period because of their urge to keep trying something new and taking risks. For that reason, some adolescents struggle to adjust to the changes that arise in their lives, which leads to aggressive behavior as a result of their inability to cope with the changes and challenges. Aggressive behavior can be defined as any planned behavior that can cause physical and emotional injury to others (Gabbey and Jewell, 2016). These types of behavior
\end{abstract}


should be avoided as it can give negative side effects to the victims as well as to the perpetrators. According to Polis Di Raja Malaysia statistics, there were a total of 1,722 reported criminal cases involving school students in 2017, down to 1,285 cases in 2018 (Berita Harian Malaysia, 2019). Furthermore, the Malaysian Education Ministry cited figures on student disciplinary incidents, citing 1,054 cases in 2018 and a total of 2,795 cases for bullying cases in 2018 (Berita Harian Malaysia, 2018). Bullying, substance abuse, and other forms of deviant behavior are the product of teenagers' aggressive behavior. Emotional dysregulation, on the other hand, is characterised as the inability or difficulty in controlling impulsive behavior. This difficulty arises when a person is experiencing negative emotions and engages in inappropriate actions in order to eliminate or reduce those negative emotions (Gratz, 2007). Aggressive actions displayed by people who are upset, unhappy, or angry exemplifies this. Accordingly, we can see how emotions drive human action in order to respond to threats and environment.

However, not everyone, including teenagers, has the capacity and ability to control their emotions appropriately. The majority of them have difficulty effectively controlling their emotions, which causes individuals, especially teenagers, to act aggressively as emotional regulation mechanisms. Therefore, the researchers conclude that treating emotional dysregulation is critical in addressing aggressive behavior in adolescents. As a matter of fact, previous research has shown the significance of the emotional component of self-emotion regulation in addressing people's mental and physical health. Past studies have documented the difficulties in regulating emotion effectively will lead to problematic behavior, mental problems, and substance abuse (Kun \& Demetrovics, 2010), self-injury (Buckholdt, Parra, \& Jobe-Shields, 2009; Mikolajczak, Petrides, \& Hurry, 2009), depression (Gross \& John, 2003; John \& Gross, 2004), anxiety (Cisler et al., 2010), "borderline" personality disorder (Gratz et al., 2006) and posttraumatic stress disorder (Tull et al., 2007) as well as aggressive behavior.

Various constructs of emotional dysregulation portray how individuals perceive and react to emotional states in a maladaptive way that contributes to aggression, according to a study conducted by Donahue et al (2014) on 318 participants ranging in age from 18 to 67 . Accordingly, they also noted that understanding the emotional response and reaction is necessary in order to understand problematic behaviors such as aggressive behavior, as the result of his study depicted the role of emotional dysregulation in aggressive behavior. The effects of emotional dysregulation on the relationship between emotionally limited men and the aggression perpetrated on 128 people were investigated in a study by Cohn et al (2010). The Gender Role Conflict scale research method (O'Heil et al., 1986) and the scale of Emotional Dysregulation were used in this study (Gratz \& Roemer, 2004). The results of the study found that non-acceptance and inability to accept emotional experience affected such relationships. In addition, the research looked at how emotional dysregulation affected men's emotional management (i.e., by suppressing emotional expression) and their participation in aggressive behavior. Male respondents having limited emotional responses were found to have difficulty in identifying emotions such as having negative view of expressing emotions. Men take extreme measures to prevent feeling uncomfortable or displaying their emotional state due to the discomfort of expressing emotions. As a result, men view aggressive behavior as a coping mechanism for dealing with emotional dysregulation and regaining control over interpersonal interactions 
involving feelings of vulnerability and negative affect (Cohn, Zeichner, \& Seibert, 2008; Jakupcak et al., 2005; O’Neil and Harway, 1997; Tull et al., 2007).

Other studies have concluded that aggressive behavior is a product of emotional control and maladaptive self-regulation (Carver, 2004; Carver \& Scheier, 1981, 2002; Hirsch, 2004) and is linked to an increased risk of aggressive behavior (Carver, 2004; Carver \& Scheier, 1981, 2002; Hirsch, 2004). As a result, people feel they can control their feelings by behaving aggressively. This heightens the individual's proclivity for aggressive behavior. Moreover, Cohn et al. (2010) discovered that emotional dysregulation (especially low emotional clarity and awareness) was linked to aggression, as measured by the electric shocks administered to cunning opponents in experimental tasks. In addition to the finding, men who indicated trouble controlling emotions were more likely to assault their spouses, according to Tager et al. (2010). Sullivan et al (2010) discovered that adolescent's inability to suppress anger and sadness was linked to their use of aggressive physical behavior and relationships (i.e., resulting in injury by damaging the victim's relationship with others) respectively. The findings indicate that a thorough explanation of the role of emotional dysregulation in aggressive behavior can yield significant benefits.

Based on previous research, it is critical to investigate internal factors and dimensions that are linked to adolescent aggression by analysing the six dimensions of emotional dysregulation (nonacceptance, goals, impulse, emotion awareness, limited strategies, and clarity) in relation to aggressive behavior. Examining the various aspects of emotional dysregulation will help us gain a better understanding of how it impacts the development and prevalence of an individual's behavior, attitudes, and behaviors. Thus, the relationship between emotional dysregulation and aggressive behavior among adolescents in Bandar Baru Bangi, Selangor. Six hypotheses were formulated in this study which are: (1) There is a significant relationship between non-acceptance and aggressive behavior; (2) There is a significant relationship between goals and aggressive behavior; (3) There is a significant relationship between impulse and aggressive behavior; (4) There is a significant relationship between emotion awareness and aggressive behavior; (5) There is a significant relationship between limited strategies and aggressive behavior, and (6) There is a significant relationship between clarity and aggressive behavior.

\section{Methodology}

The study used a survey research design, in which questionnaires were distributed to adolescents who met the inclusion criteria. A total of 159 adolescents took part in the study by completing an online Google Form with a series of questionnaires created by the researcher. The respondents were chosen by convenience sampling in the researcher's neighbourhood, which is in Bandar Baru Bangi, Selangor. The questionnaire used in this study comprised of three parts namely demographic profile, Difficulties in Emotion Regulation Scale (DERS-18), and Buss Perry Aggression Questionnaire (BPAQ). Difficulties in emotion regulation consisted of six dimensions: i) non-acceptance; ii) goals; iii) impulse; iv) emotion awareness; v) limited strategies; and vi) clarity which each comprised three items that resulted a total of 18 items. The responses used a five-point Likert scale with 5=Almost Always, 4=Most of the Time, $3=$ About Half the Time, 2=Sometimes, and 1=Almost Never. However, some items are marked according to the reverse scoring such as item number 1, 4, and 6 with 1=Almost Always and 5=Almost Never. 
The Buss Perry Aggression Questionnaire (BPAQ) measures the tendency of individuals to behave aggressively in terms of physical aggression, verbal aggression, anger, and hostility which consists of a total of 29 items. The responses used a five-point Likert scale with $5=$ Extremely Characteristic of $\mathrm{Me}$, 4=Somewhat Characteristic of Me, 3=Neither Uncharacteristic nor Characteristic of Me, 2=Somewhat Uncharacteristic of Me, and 1=Extremely Uncharacteristic of Me. A pilot study was conducted with 50 respondents and analysis of reliability showed that all six dimensions have satisfactory reliability with Cronbach alphas of .501 for non-acceptance, .669 for goals, .822 for impulse, .652 for emotion awareness, .758 for limited strategies, and .580 for clarity. Next, BPAQ showed the same reliability results with all four dimensions have satisfactory reliability with Cronbach alphas of .836 for physical aggression, .709 for verbal aggression, .889 for anger, and .814 for hostility. Data from the actual study were then analyzed using descriptive and inferential statistics.

\section{Results}

\section{Demographic Profile}

Table 1 shows the demographic profile of the respondents. A total of 71 male respondents $(44.7 \%)$ and 88 female respondents (55.3\%) took part in the survey. 42 respondents $(26.4$ percent) were between the ages of 12 and 14, 66 respondents ( 41.5 percent) were between the ages of 15 and 17, and 51 respondents (32.1 percent) were between the ages of 18 and 20. Malay respondents accounted for 93.1 percent of the total. Meanwhile, with a total of 6 respondents ( 3.8 percent) and 5 respondents ( 3.1 percent), the Chinese and Indians were two minorities. The religious distribution of the respondents indicates that Islam has the largest number of 148 respondents (93.1\%), followed by Hinduism with 5 respondents (3.1\%), 4 respondents Buddhism (2.5\%), and Christian with only 2 respondents (1.3\%).

\section{Table 1}

Respondents' demographic profile

\begin{tabular}{llll}
\hline $\begin{array}{l}\text { Demograph } \\
\text { y }\end{array}$ & & $\begin{array}{l}\text { Frequenc } \\
\text { y }\end{array}$ & $\begin{array}{l}\text { Percentage } \\
\text { (\%) }\end{array}$ \\
\hline Gender & Male & 71 & 44.7 \\
Age & Female & 88 & 55.3 \\
& $12-14$ y/o & 42 & 26.4 \\
National & $15-17$ y/o & 66 & 41.5 \\
& Malay & 148 & 32.1 \\
& Indian & 5 & 93.1 \\
Religious & Chinese & 6 & 3.1 \\
& Islam & 148 & 3.8 \\
& Hinduism & 5 & 93.1 \\
& Buddhism & 4 & 3.1 \\
& Christian & 2 & 2.5 \\
\hline
\end{tabular}

The hypotheses on the relationship between six dimensions of emotional dysregulation and aggressive behavior were analyzed using Pearson correlation. 
H1: There is a significant relationship between non-acceptance and aggressive behavior Results in Table 2 showed that there was a significant positive relationship between nonacceptance and the dimensions of aggressive behavior; physical aggression, verbal aggression, anger and hostility dimension, $r=.245, p<0.05 ; r=.234, p<0.05 ; r=.204, p<0.05$; and $r=.299$, $p<0.05$. Therefore, hypothesis 1 was accepted.

H2: There is a significant relationship between goals and aggressive behavior

Results also showed that there was a significant and positive relationship between goals and the aggressive behavior dimensions; physical aggression, verbal aggression, anger and hostility dimension, $r=.174, p<0.05 ; r=.159, p<0.05 ; r=.183, p<0.05$; and $r=.244, p<0.05$. Based on the results, hypothesis 2 was accepted.

H3: There is a significant relationship between impulse and aggressive behavior

Findings showed that there was a significant and positive relationship between impulse and three dimensions of aggressive behavior; physical aggression, verbal aggression, and hostility, $r=.272$, $p<0.05 ; r=.248, p<0.05 ;$ and $r=.297, p<0.05$. Impulse also showed a significant and positive relationship with anger dimension with $r=.307, p<0.05$. Thus, hypothesis 3 was accepted.

H4: There is a significant relationship between emotion awareness and aggressive behavior Findings also showed that there was a significant and negative relationship between emotion awareness and the dimensions of aggressive behavior; physical aggression, verbal aggression, anger, and hostility, $r=-.217, p<0.05 ; r=-.215, p<0.05 ; r=-.241, p<0.05 ;$ and $r=-.166, p<0.05$. Based on the results, hypothesis 4 was accepted.

H5: There is a significant relationship between limited strategies and aggressive behavior Results showed that there was a significant and positive relationship with limited strategies and the dimensions of aggressive behavior; physical aggression, verbal aggression, and anger, $r=.253$, $p<0.05 ; r=.267, p<0.05 ;$ and $r=.267, p<0.05$ while, the association of limited strategies with hostility dimension also showed a significant and positive result with $r=.332, p<0.05$. Thus, hypothesis 5 was accepted.

H6: There is a significant relationship between clarity and aggressive behavior

Findings showed that there was a significant and positive relationship with clarity and the dimensions of aggressive behavior; physical aggression, verbal aggression, and anger, $r=.221, p$ $<0.05 ; r=.280, p<0.05$; and $r=.280, p<0.05$. In addition, the relation of clarity with hostility dimension also showed a significant and positive result with $r=.306, p<0.05$. Therefore, hypothesis 6 was accepted. 
Table 2 Pearson Correlation Between Emotional Dysregulation and Aggressive Behavior

\begin{tabular}{|c|c|c|c|c|c|c|c|c|c|c|}
\hline Dimension & 1 & 2 & 3 & 4 & 5 & 6 & 7 & 8 & 9 & $\begin{array}{l}1 \\
0\end{array}$ \\
\hline $\begin{array}{l}\text { 1. Non- } \\
\text { acceptance }\end{array}$ & 1 & & & & & & & & & \\
\hline 2. Goals & $\begin{array}{l}.588 * \\
*\end{array}$ & 1 & & & & & & & & \\
\hline Impulsive & $\begin{array}{l}.600 * \\
*\end{array}$ & $\begin{array}{l}.726 * \\
*\end{array}$ & 1 & & & & & & & \\
\hline 4. Emotion & & - & - & & & & & & & \\
\hline Awareness & -.054 & $\begin{array}{l}.173 * \\
*\end{array}$ & $\begin{array}{l}.156^{*} \\
*\end{array}$ & 1 & & & & & & \\
\hline Strategies & $\begin{array}{l}.654^{*} \\
*\end{array}$ & $\begin{array}{l}.652^{*} \\
*\end{array}$ & $\begin{array}{l}.805^{*} \\
*\end{array}$ & -.087 & 1 & & & & & \\
\hline $\begin{array}{l}6 . \quad \text { Emotion } \\
\text { Clarity }\end{array}$ & $\begin{array}{l}.593^{*} \\
*\end{array}$ & $\begin{array}{l}.507^{*} \\
*\end{array}$ & $\begin{array}{l}.523 * \\
*\end{array}$ & $-.173 *$ & $\begin{array}{l}.605^{*} \\
*\end{array}$ & 1 & & & & \\
\hline $\begin{array}{l}7 . \quad \text { Physical } \\
\text { Aggression }\end{array}$ & $\begin{array}{l}.245^{*} \\
*\end{array}$ & $\begin{array}{l}.174^{*} \\
*\end{array}$ & $\begin{array}{l}.272 * \\
*\end{array}$ & $\begin{array}{l}.217^{*} \\
*\end{array}$ & $\begin{array}{l}.253^{*} \\
*\end{array}$ & $\begin{array}{l}.221 * \\
*\end{array}$ & 1 & & & \\
\hline $\begin{array}{l}8 . \quad \text { Verbal } \\
\text { Aggression }\end{array}$ & $\begin{array}{l}.234^{*} \\
*\end{array}$ & $\begin{array}{l}.159 * \\
*\end{array}$ & $\begin{array}{l}.248^{*} \\
*\end{array}$ & $\begin{array}{l}- \\
.215^{*} \\
*\end{array}$ & $\begin{array}{l}.267 * \\
*\end{array}$ & $\begin{array}{l}.280 * \\
*\end{array}$ & $\begin{array}{l}.876^{*} \\
*\end{array}$ & 1 & & \\
\hline Anger & $\begin{array}{l}.204^{*} \\
*\end{array}$ & $\begin{array}{l}.183 * \\
*\end{array}$ & $\begin{array}{l}.307^{*} \\
*\end{array}$ & $\begin{array}{l}- \\
.241 * \\
*\end{array}$ & $\begin{array}{l}.292 * \\
*\end{array}$ & $\begin{array}{l}.271^{*} \\
*\end{array}$ & $\begin{array}{l}.885^{*} \\
*\end{array}$ & .844 & 1 & \\
\hline 10. Hostility & $\begin{array}{l}.299 * \\
*\end{array}$ & $\begin{array}{l}.244^{*} \\
*\end{array}$ & $\begin{array}{l}.297^{*} \\
*\end{array}$ & $\begin{array}{l}- \\
.166^{*} \\
*\end{array}$ & $\begin{array}{l}.332 * \\
*\end{array}$ & $\begin{array}{l}.306 * \\
*\end{array}$ & $\begin{array}{l}.777^{*} \\
*\end{array}$ & $\begin{array}{l}.842^{*} \\
*\end{array}$ & $\begin{array}{l}.834^{*} \\
*\end{array}$ & 1 \\
\hline
\end{tabular}

*Correlation is significant at 0.05 (2-tailed)

** Correlation is significant at 0.01 (2-tailed)

\section{Discussion}

The results of the study show a significant relationship between emotional dysregulation and aggressive behavior. This result describes the dimension of emotional dysregulation i.e. nonacceptance, goals, impulsive, awareness, strategies and clarity as well as dimensions of aggressive behavior i.e. physical aggression, verbal aggression, anger and hostility. Results have found all dimensions of emotional dysregulation (i.e., lack of acceptance, goals, impulsive, awareness, strategy and clarity) relate significantly to all dimensions of aggressive behavior (i.e. physical aggression, verbal aggression, anger and hostility). However, only emotion awareness dimension showed a negative but significant relationship with aggressive 
behavior. The results of this study indicate that aggressive adolescent behavior is linked to adolescents' lack of awareness of emotional response. The findings of this study are in line with the findings of many previous studies, which show that a lack of ability to regulate emotion such as not receiving emotional response (non-acceptance), difficulty engaging in purposeful behavior in an emotional state goals (goals), difficulty controlling impulsive behavior when in an emotional state negative (impulsive), lack of awareness of the response (awareness), access that is limited to emotional regulation strategies and lack of emotional response (clarity) relates consistently to the tendency of aggressive behavior among various study samples such as normal individuals, psychiatric patients, juvenile offenders and criminals (Donahue et al., 2014; Garofalo \& Velotti, 2017; Miller, Vachon, \& Aalsma, 2012; Roberton, Daffern, \& Bucks, 2014, 2015; Velotti et al., 2016). The study of Donahue et al (2014) in particular states that certain deficiencies in the part of the emotional regulation of the individual such as lack of emotional awareness have to do with the physical aggression of the individual.

The findings of the study can then be justified through a model of emotion dysregulation (EDM) which explains that individuals with emotional dysregulation have these four components namely: i) individuals who have emotional intensity which exceeds or is out of control as compared to others, whether negative or positive emotions, ii) individuals who have a poor understanding of their own emotions, iii) individuals who have many negative attitudes towards emotions such as having the perception that his emotional state or emotional experience is having a detrimental effects, and iv) the implementation of maladaptive emotional regulation strategies causing the emotion states becoming more unmanageable compared to the regulated emotional state (MacLaughlin et al., 2011). Hence, individuals who are incapable of obtaining and applying information regarding their emotional states in an adaptive manner, will indirectly affect the individiual's emotional response and behavioral strategies in regulating their emotions effectively.

Additionally, when an individual is experiencing discomfort due to the emotional intensity he experiences, particularly negative emotions such as sadness, anger, frustration and the like, the individual's emotional state becomes even more unbalanced and uncomfortable. Such emotional discomfort and imbalance need to be regulated adaptively and appropriately to enable the individual to respond and behave in accordance with the environment. However, due to the lack of emotional regulatory elements in terms of acceptance of emotional response, involvement in behavior toward goals, controlling impulsive behavior, emotional response awareness, use of emotional regulation strategies and clarity emotional response or in short the individual has difficulty regulating emotions (emotional dysregulation) leads the individual to experience negative feelings in an extreme manner such as anger as a secondary response to emotional experiences which is not pleasant. The relationship to the development of expressions of anger and hostility (i.e. feelings of individuals who feel their environment as a threat) in turn causes individuals to be more prone to aggressive behavior. At the same time, the findings of previous studies also support the findings of this study suggesting that individuals are incapable of controlling and refraining their behavior from impulsive actions when experiencing stress, difficulty in engaging in goal-directed behavior, limited access to emotional regulation strategies, and difficulty in paying attention to emotions while experiencing negative emotional feelings, they also lack the clarity of current emotional state in relation to physical aggressive behavior, verbal aggression, anger and 
hostility displayed by adolescent individuals (Cohn et al., 2010; Caspi et al., 1996; Miller et al., 2012; Farrington, 2005; Garofalo et al., 2016; Vaughn et al., 2016; Velotti et al., 2015a).

This is due to the individual's desire to minimize emotions, controlling emotions excessively or expressing emotions in inappropriate ways such as excessive worrying, harboring emotions or emotional outbursts. Such attempts are considered ineffective strategies because they are unable to deal and control these emotions. However, the attempt to implement adaptive emotional regulation strategies excessively are likely to lead to opposite result. In short, individuals who use maladaptive emotional regulation strategies cause the subsequent increase in negative emotions that leads to aggressive behavior. However, the association of specific emotion dysregulation dimensions with aggressive behavior does not necessarily imply that other dimensions of emotional dysregulation are irrelevant with aggressive behavior instead, it can be explained through different and more unique connections and explanations. Accordingly, the researchers conclude that individuals who are vulnerable to strong emotional intensity are more likely to use maladaptive emotional strategies to minimize their emotions and in aspects of this study, individuals are more likely to behave aggressively as one of the maladaptive strategies to control their emotions excessively or express emotions inappropriately.

\section{Conclusion}

This study has shown that there was a significant relationship between emotional dysregulation and aggressive behavior. The effect size, the respondents' criteria and sampling technique are some of this study's shortcomings, which are due to the limited sample size and use of non-clinical respondents. The use of a sampling method with low credibility and precision makes it more difficult for researchers to obtain meaningful and strong results, as well as to generalize the findings to a larger population. Therefore, future research is needed to focus on the study design in which internal problems (internalizing problem) such as difficulty regulating emotions or emotional dysregulation and externalizing problems such as aggressive behavior, are encouraged to use a mixed study design (mixed methods) as well as longitudinal study compared to only using cross sectional study due to its ability to produce more effective results and at the same time be able to get rid of various biases or errors outside the study that the researchers could not control. Other than that, future researchers are encouraged to set inclusive and exclusive characteristics such as high risk or clinical adolescents with age from 10 to 19 years, have a history of engaging in aggressive behavior, show signs of experiencing emotional dysregulation in order for the researcher to narrow down the appropriate respondents. Lastly, future researchers are expected to further study the dimensions of emotional dysregulation in detail and specific compared to the previous findings which only focus it in general. In fact, the specialization on the dimensions of certain research variables further facilitates the researchers to direct the research conclusively. In conclusion, the results of this study show that emotional dysregulation is strongly linked to aggressive behavior in adolescents, such as physical aggression, verbal aggression, anger, and hostility

\section{References}

Berita Harian Malaysia. (2019). Jenayah dalam kalangan pelajar masih membimbangkan. https://www.bharian.com.my/berita/kes/2019/11/627250/jenayah-dalam-kalanganpelajar-masih- membimbangkan 
Berita Harian Malaysia. (2018). 1,440 kes jenayah babit pelajar sekolah tahun lalu. https://www.bharian.com.my/berita/nasional/2018/10/489910/1440-kes-jenayahbabit-pelajar- sekolah-tahun-lalu

Borders, A., Earleywine, M., \& Jajodia, A. (2010). Could mindfulness decrease anger, hostility, and aggression by decreasing rumination? Aggressive Behavior: Official Journal of the International Society for Research on Aggression, 36(1), 28-44.

Buss, A. H., \& Perry, M. (1992). The aggression questionnaire. Journal of Personality and Social Psychology, 63(3), 452.

Cohen, J. W. (1988). Statistical power analysis for the behavioral sciences (2nd. Ed.). Hillsdale, New Jersey: Lawrence Erlbaum Associates.

Cohn, A. M., Jakupcak, M., Seibert, L. A., Hildebrandt, T. B., \& Zeichner, A. (2010). The role of emotion dysregulation in the association between men's restrictive emotionality and use of physical aggression. Psychology of Men \& Masculinity, 11(1), 53-64.

Coker, T. R., Elliott, M. N., Schwebel, D. C., Hertz M. F., Peskin, M. F. \& Schuster, M. A. (2014). Media violence exposure and physical aggression in fifth-grade children. Academic Pediatric Journal, 15(1), 82-88.

Donahue, J. J., Goranson, A. C., McClure, K. S., \& Van Male, L. M. (2014). Emotion dysregulation, negative affect, and aggression: A moderated, multiple mediator analysis. Personality and Individual Differences, 70, 23-28. doi:10.1016/j.paid.2014.06.009.

Gabbey, A. C. Jewell, T. (2016). What is aggressive behaviour? http://www.healthlive.com/health/aggressivebehaviour.

Garofalo, C., \& Velotti, P. (2017). Negative emotionality and aggression in violent offenders: The moderating role of emotion dysregulation. Journal of Criminal Justice, 51, 9-16.

Gratz, K. L., \& Roemer, L. (2004). Multidimensional assessment of emotion regulation and dysregulation: development, factor structure, and initial validation of the difficulties in emotion regulation scale. Journal of Psychopathology and Behavioral Assessment, 26(1), 41-54.

Gratz, K. L., Rosenthal, M. Z., Tull, M. T., Lejuez, C. W., \& Gunderson, J. G. (2006). An experimental investigation of emotion dysregulation in borderline personality disorder. Journal of Abnormal Psychology, 115(4), 850.

Gratz, K. L. (2007). Targeting emotion dysregulation in the treatment of self-injury. Journal of Clinical Psychology, 63(11), 1091-1103.

Heppner, W. L., Kernis, M. H., Lakey, C. E., Campbell, W. K., Goldman, B. M., Davis, P. J., \& Cascio, E. V. (2008). Mindfulness as a means of reducing aggressive behavior: Dispositional and situational evidence. Aggressive Behavior: Official Journal of the International Society for Research on Aggression, 34(5), 486-496.

McLaughlin, K. A., Hatzenbuehler, M. L., Mennin, D. S., \& Nolen-Hoeksema, S. (2011). Emotion dysregulation and adolescent psychopathology: A prospective study. Behaviour Research and Therapy, 49(9), 544-554.

Miller, D. J., Vachon, D. D., \& Aalsma, M. C. (2012). Negative affect and emotion dysregulation: Conditional relations with violence and risky sexual behavior in a sample of justiceinvolved adolescents. Criminal Justice and Behavior, 39(10), 1316-1327.

Roberton, T., Daffern, M., \& Bucks, R. S. (2012). Emotion Regulation and Aggression. Aggression and Violent Behavior, 17(1), 72-82. doi:10.1016/j.avb.2011.09.006.

Roberton, T., Daffern, M., \& Bucks, R. S. (2014). Maladaptive emotion regulation and aggression in adult offenders. Psychology, Crime \& Law, 20(10), 933-954. 
Roberton, T., Daffern, M., \& Bucks, R. S. (2015). Beyond anger control: Difficulty attending to emotions also predicts aggression in offenders. Psychology of Violence, 5(1), 74.

Singh, N. N., Lancioni, G. E., Winton, A. S., Adkins, A. D., Wahler, R. G., Sabaawi, M., \& Singh, J. (2007). Individuals with mental illness can control their aggressive behavior through mindfulness training. Behavior modification, 31(3), 313-328.

Sullivan, T. N., Helms, S. W., Kliewer, W., \& Goodman, K. L. (2010). Associations between sadness and anger regulation coping, emotional expression, and physical and relational aggression among urban adolescents. Social Development, 19(1), 30- 51.

Tager, D., Good, G. E., \& Brammer, S. (2010). "Walking Over 'Em": An exploration of relations between emotion dysregulation, masculine norms, and intimate partner abuse in a clinical sample of men. Psychology of Men \& Masculinity, 11(3), 233- 239.

Velotti, P., Garofalo, C., Callea, A., Bucks, R. S., Roberton, T., \& Daffern, M. (2016). Exploring anger among offenders: The role of emotion dysregulation and alexithymia.Psychiatry, Psychology and Law, 24(1), 128-138. doi:10.1080/13218719.2016.116463. 